\title{
Analysis and Design of LCL Filter with Passive Damping Circuits for Three-phase Grid-connected Inverters
}

\author{
Hyo Min Ahn*, Chang-Yeol Oh*, Won-Yong Sung*, Jung-Hoon Ahn* \\ and Byoung Kuk Lee ${ }^{\dagger}$
}

\begin{abstract}
The analysis and design process of the LCL filter with passive damping circuits for threephase grid-connected inverter are presented based on the generalized model of LCL filter. Several types of the passive damping circuits in previous studies could be compared and analyzed by using the generalized model considering various design criteria of passive damping circuits. According to the analysis in this paper, a reasonable configuration of passive damping circuits for three-phase gridconnected inverters is proposed. The validity of the proposed design process is verified by informative simulation and experimental results.
\end{abstract}

Keywords: Passive damping circuit, LCL filter, Grid-connected inverter, Three-phase inverter, Highorder filter

\section{Introduction}

The high quality of output currents is a major factor in the design of grid-connected inverters. Therefore, a lowpass filter (LPF) that has a high attenuation ratio of highorder harmonic currents is necessary to be placed between the utility grid and the inverter [1-6]. When L filters and LC filters are used in grid-connected inverters, they are designed to be large in order to secure the high attenuation ratio in the high frequency band [6]. However, LCL filters are small and have sufficiently high attenuation ratios in the high frequency band, relative to L filters and LC filters. Therefore, they are commonly used in grid-connected inverters in the previous studies [1-7].

However, at the resonant frequency of the LCL filter, it has a very high resonant peak [1-4]. Therefore, output currents contain high resonant currents that cause divergence of the output currents. In addition, LCL filters are unstable because all poles and zeroes are located in the pure imaginary axis [10]. For these reasons, various methods to solve this problem have been suggested. Among these methods, a passive damping method that can reduce the resonant peak by adding passive components to an LCL filter has several advantages. First, it can be easily applied to LCL filters. In addition, the passive damping method does not require additional sensors or control loops [9]. For these reasons, in previous studies, many types of passive damping circuits have been studied. However, in these studies, comparison and analysis of various types of

$\dagger$ Corresponding Author: Department of Electrical and Computer Engineering, Sungkyunkwan University, Korea.

(bkleeskku@skku.edu)

* Department of Electrical and Computer Engineering, Sungkyunkwan University, Korea. (wihha@skku.edu)

Received: April 1, 2016; Accepted: August 6, 2016 passive damping circuits have not been seriously considered and only specific types of passive damping circuits have been studied $[2-4,9]$. Thus, the design of reasonable passive damping circuits for LCL filters to satisfy various design criteria has not been sufficiently carried out [1].

Therefore, this paper analyzes various types of passive damping circuits and presents a design process of the LCL filter with passive damping circuits based on various design criteria. For the analysis and design procedure, a generalized model of the LCL filter with passive damping circuits containing various combinations of passive components is suggested for a clear design of an LCL filter with passive damping circuits. Finally, the design process for the proposed model is verified by means of simulations and experiments.

\section{Design Process and Evaluation of LCL Filter}

A single-phase model, as shown in Fig. 1(a), is used to simplify the analysis and design of the three-phase LCL filter and passive damping circuits $[1,2,5,6]$. An ideal utility grid voltage does not have high-order harmonic components. Therefore, it can be treated as a short circuit in the high frequency band. The parasitic resistances $\left(R_{i}\right.$ and $\left.R_{g}\right)$ in filter inductors $\left(L_{i}\right.$ and $\left.L_{g}\right)$ can be ignored because they are sufficiently small compared to filter inductance at high frequencies. For these reasons, Fig. 1(a) can be transformed into Fig. 1(b). Using both models in Figs. 1(a) and (b), the analysis and design of the LCL filter with passive damping circuits are performed. Based on Fig. 1(b), the following equations can be derived and these are used to analyze the transfer functions of the LCL filter with passive damping circuits $[1,5-7]$. 


$$
\begin{aligned}
G_{g}(s)=\frac{i_{g . h}(s)}{V_{\text {inv.h }}(s)} & \approx \frac{1}{L_{i} L_{g} C_{f} s^{3}+\left(L_{i}+L_{g}\right) s} \\
\omega_{r} & =\sqrt{\frac{L_{i}+L_{g}}{L_{i} L_{g} C_{f}}}
\end{aligned}
$$

The first step in the design of the LCL filter is to determine the value of the filter capacitor $\left(C_{f}\right)$ in the singlephase model. $C_{f}$ for the three-phase and wye-connected LCL filter can be calculated by using an allowable ratio of reactive power $(\beta)$ at the fundamental frequency as (3) $[5,6]$.

The inverter-side inductor $\left(L_{i}\right)$ can be calculated by the maximum allowable ripple of the inverter-side current $\left(\Delta i_{\text {i.max }}\right)$. In the case of the space vector pulse width modulation (SVPWM) inverter, the ripple current of the inverter side can be expressed by (4) and $L_{i}$ can be calculated as shown in (5) by using (4) [5]. In previous studies, the allowable ripple current $\left(\Delta i_{i \text { max }}\right)$ is generally designed to be from 15 to $25 \%$ of the fundamental currents, based on the trade-off between losses of the switching elements and the inverter-side inductor [5].

$$
\begin{gathered}
C_{f} \leq \beta \frac{2 P_{\text {rate }}}{3 \omega_{\text {grid }} V_{\text {LL.rate }}{ }^{2}} \\
\Delta i_{i \text { max }}=\frac{V_{D C \text {-link }}-V_{\text {grid.peak }}}{4\left(2 L_{i}\right) f_{s}} \\
L_{i}=\frac{V_{D C \text {-link }}-V_{\text {grid.peak }}}{8 \Delta i_{i \text {.max }} f_{s}}
\end{gathered}
$$

Using the ratio of inverter-side to grid-side current $(\alpha)$, the grid-side inductor $\left(L_{g}\right)$ can be designed. The short circuit model shown in Fig. 1(b) can be converted into the

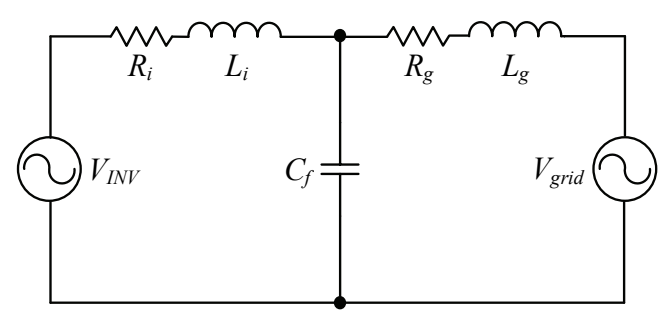

(a) Equivalent circuit of LCL filter at fundamental frequency

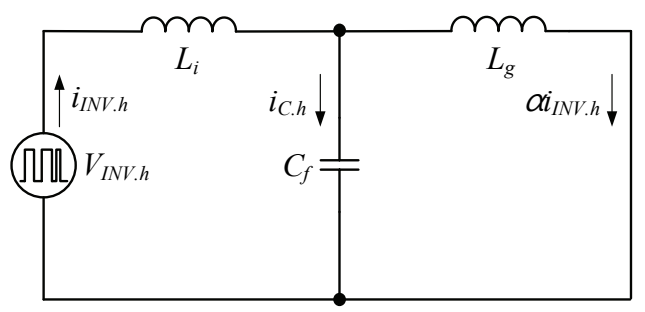

(b) Equivalent circuit of LCL filter at high frequencies

Fig. 1. Single-phase equivalent models of grid-connected inverter with LCL filter model in Fig. 2 because the calculated inverter-side ripple current of (4) can be considered as equivalent to a highorder harmonic current source $\left(i_{I N V . . h}\right)$. In this model, $\alpha$ and the grid-side current $\left(\alpha i_{I N V . h}\right)$ can be derived as (6). Using (6), $L_{g}$ can be expressed as (7) $[1,6,7]$.

$$
\begin{gathered}
\alpha i_{I N V . h}=\left|\frac{1}{1+C_{f} L_{g} s^{2}}\right| i_{I N V . h} \\
L_{g}=\frac{1+\alpha}{\alpha \omega_{s}^{2} C_{f}}
\end{gathered}
$$

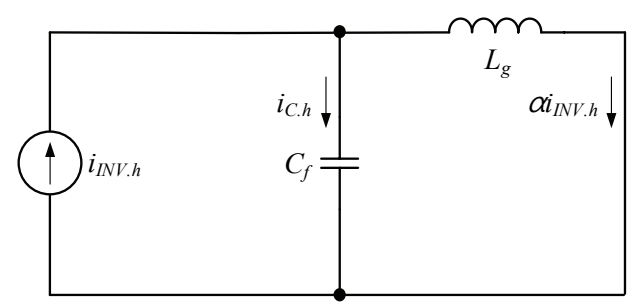

Fig. 2. Equivalent circuit with inverter-side current

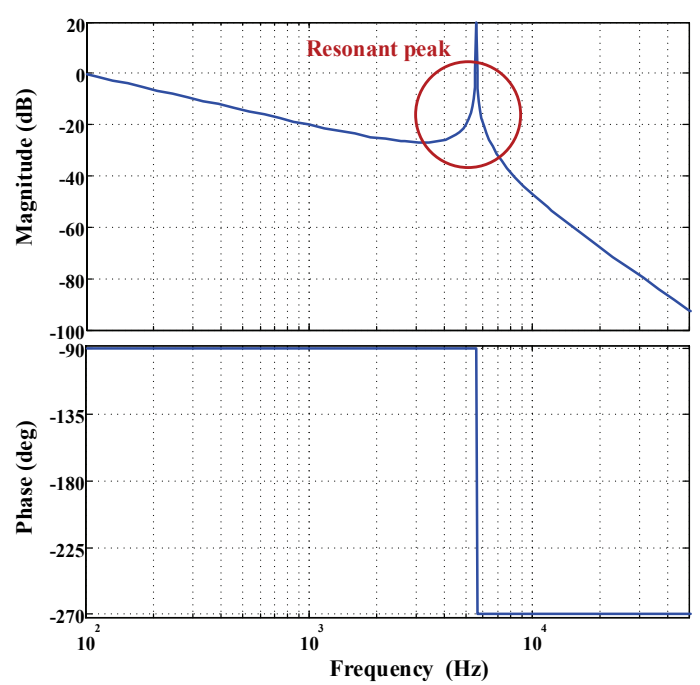

Fig. 3. Frequency response of LCL filter without damping circuits

Table 1. Specifications of grid-connected inverter system

\begin{tabular}{c|c}
\hline Parameter & Value \\
\hline Grid voltage $\left(V_{\text {grid }}\right)$ & $3 ø 380 \mathrm{~V}_{\text {LL.rms }}$ \\
\hline Grid frequency $\left(f_{\text {grid }}\right)$ & $60 \mathrm{~Hz}$ \\
\hline Rated power $\left(P_{\text {rate }}\right)$ & $10 \mathrm{~kW}$ \\
\hline Switching frequency $\left(f_{s}\right)$ & $10 \mathrm{kHz}$ \\
\hline Inverter-side ripple current $\left(\Delta i_{\text {i.max }}\right)$ & $3.2 \mathrm{~A}_{\text {peak }}$ \\
\hline Grid-side ripple current $\left(\Delta i_{\text {i.max }}\right)$ & $1.5 \mathrm{~A}_{\text {peak }}$ \\
\hline
\end{tabular}

Table 2. Design parameters of LCL filter

\begin{tabular}{c|c}
\hline Parameter & Value \\
\hline Inverter side inductor $\left(L_{i}\right)$ & $1.31 \mathrm{mH}$ \\
\hline Grid side inductor $\left(L_{g}\right)$ & $0.27 \mathrm{mH}$ \\
\hline Filter capacitor $\left(C_{f}\right)$ & $3.0 \mathrm{uF}$ \\
\hline
\end{tabular}


Based on the specifications listed in Table 1 for threephase grid-connected inverter, the LCL filter can be designed as in Table 2 .

The frequency response of the LCL filter in Table 2 can be depicted in Fig. 3. As shown in Fig. 3, it has been confirmed that the LCL filter is unstable, and in order to stabilize it, passive damping circuits should be used. However, passive damping circuits degrade the LCL filter such as additional losses and a decreased attenuation ratio of harmonic currents and power density. Therefore, analysis and comparison of various types of passive damping circuits are necessary to select an optimal case.

\section{LCL Filter Models with Passive Damping Circuits}

\subsection{Generalized model of LCL filter with passive damping circuits}

Comparison and analysis of many types of passive damping circuits are necessary to design reasonable combinations of passive components for grid-connected inverters. In order that, a generalized model of an LCL filter with passive damping circuits is proposed as shown in Fig. 4. Unlike in previous studies, the characteristics of each passive damping circuit are analyzed and compared based on the locations and combinations of passive components using this model except for certain types of passive damping circuits such as large passive components and added resonant frequencies [1].

When calculating the transfer functions using Table 3 and (8), the unused damper and passive components are treated as open or short according to the connection or position of passive components. For example, when $R_{d}$ in damper $D$ is selected for adding one zero and one pole in the left half plain, damper $A$ are treated as short, damper $B$ and $C$ are treated as open and $L_{d}$ and $C_{d}$ in damper $D$ are treated as short. After this process, the transfer functions can be calculated by substituting design parameters in (8). Based on the calculated transfer functions in Table 3 and Fig. 4, frequency responses by combinations and locations

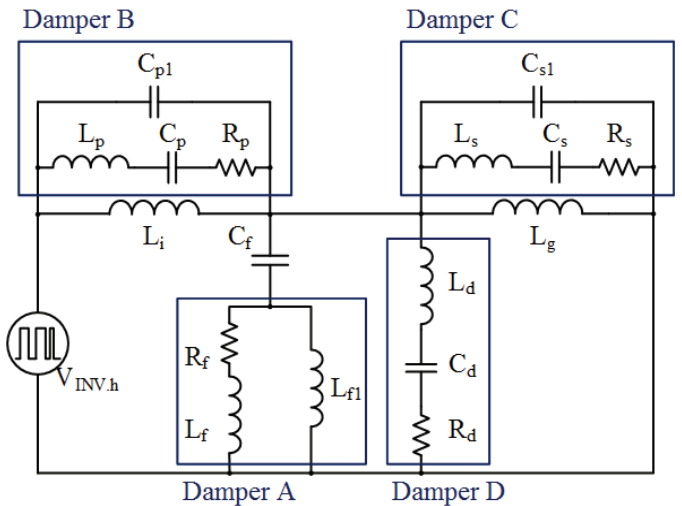

Fig. 4. Generalized model of LCL filter with passive damping circuit

of passive components in each damper are depicted in Fig. 5. Fig. 5 shows that although each damper can reduce the resonant peak with only damping resistors, when filter capacitors or inductors are connected to damping resistors, the characteristics of the LCL filter with passive damping circuits are changed more than when using passive damping circuits without inductors and capacitors. Therefore, various types of passive damping circuits and design criteria should be considered in the design. In addition, reasonable passive damping circuits should be selected.

$$
G_{g}(s)=A(s) \cdot B(s) \cdot C(s) \cdot D(s) \cdot K(s)
$$

\subsection{Design process of LCL filter with passive damping circuits}

The design criteria of the passive damping circuits are as follows: First, the magnitude at the resonant frequency should be sufficiently small. In the case of this criterion, all configurations of dampers in Fig. 5 satisfy this condition.

Second, degradation of the attenuation ratio in the high frequency band should be small. When damping circuits are applied to the LCL filter, the attenuation ratio decreases and it causes a decrease in the quality of the output current. Therefore, when the quality of the output currents is a

Table 3. Transfer function of each damper in Fig. 4

\begin{tabular}{c|c|c}
\hline Damper & Notation & $\frac{C_{f} L_{f} L_{f 1} s^{2}+L_{f} s+R_{f}}{\left(C_{f} L_{f} L_{g} L_{i} s^{4}+C_{f}\left(L_{f} L_{g} R_{f}+L_{f} L_{i} R_{f}+L_{g} L_{i} R_{f}\right) s^{3}+L_{f}\left(L_{g}+L_{i}\right) s^{2}+R_{f}\left(L_{g}+L_{i}\right) s\right.}$ \\
\hline$B$ & $A(s)$ & $\frac{C_{p} C_{p 1} L_{i} s^{4}+\left(C_{p} L_{i}+C_{p 1} L_{i}\right) s^{2}+C_{p} R_{p} s+1}{\left(C_{f} C_{p} L_{g} L_{i} R_{p}+C_{p} C_{p 1} L_{g} L_{i} R_{p}\right) s^{4}+\left(C_{f} L_{g} L_{i}+C_{p} L_{g} L_{i}+C_{p 1} L_{g} L_{i}\right) s^{3}+\left(C_{p} L_{g} R_{p}+C_{p} L_{i} R_{p}\right) s^{2}+\left(L_{g}+L_{i}\right) s}$ \\
\hline$C$ & $B(s)$ & $\frac{\left(C_{s} L_{g}+C_{s 1} L g\right) s^{2}+L_{g} R_{s} s+1}{\left(C_{f} L_{g} L_{i}+C_{s} L_{g} L_{i}+C_{s 1} L_{g} L_{i}\right) s^{3}+R_{s} L_{g} L_{i} s^{2}+\left(L_{g}+L_{i}\right) s}$ \\
\hline$D$ & $C(s)$ & $\frac{C_{d} L_{d} s^{2}+C_{d} R_{d} s+1}{C_{d} C_{f} L_{d} L_{g} L_{i} s^{3}+C_{d} C_{f} L_{g} L_{i} R_{d} s^{4}+\left(C_{d} L_{d} L_{g}+C_{d} L_{d} L_{i}+C_{d} L_{g} L_{i}+C_{f} L_{g} L_{i}\right) s^{3}+C_{d} R_{d}\left(L_{g}+L_{i}\right) s^{2}+\left(L_{g}+L_{i}\right) s}$ \\
\hline- & $D(s)$ & $\left(L_{i} L_{g} C_{f} s^{3}+\left(L_{i}+L_{g}\right) s\right)^{3}$ \\
\hline
\end{tabular}




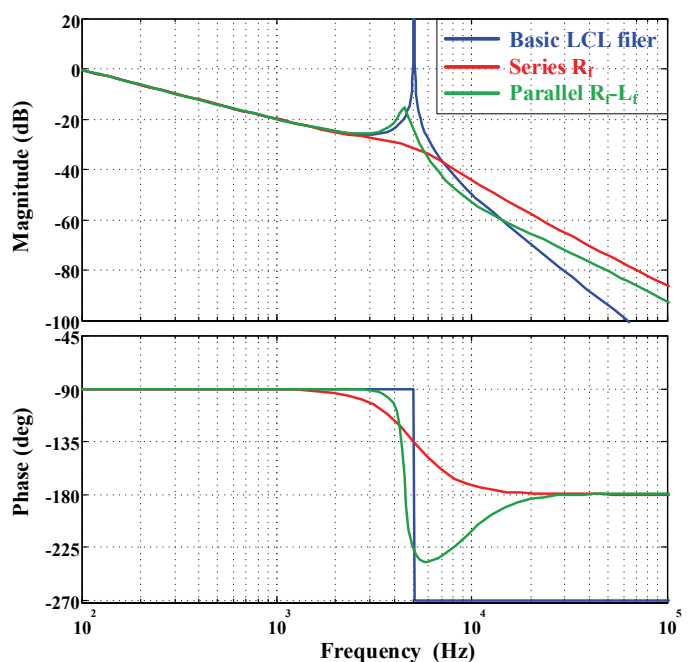

(a) LCL filter with damper $A$

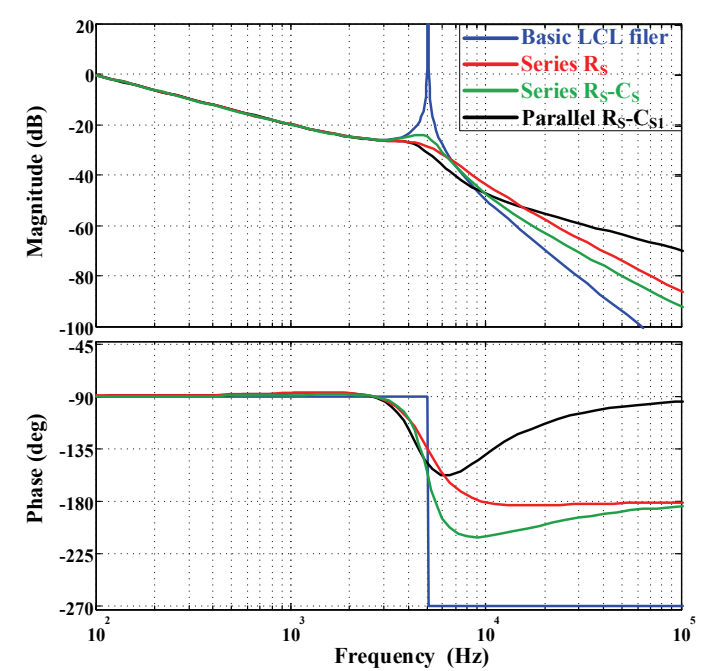

(d) LCL filter with damper $A$

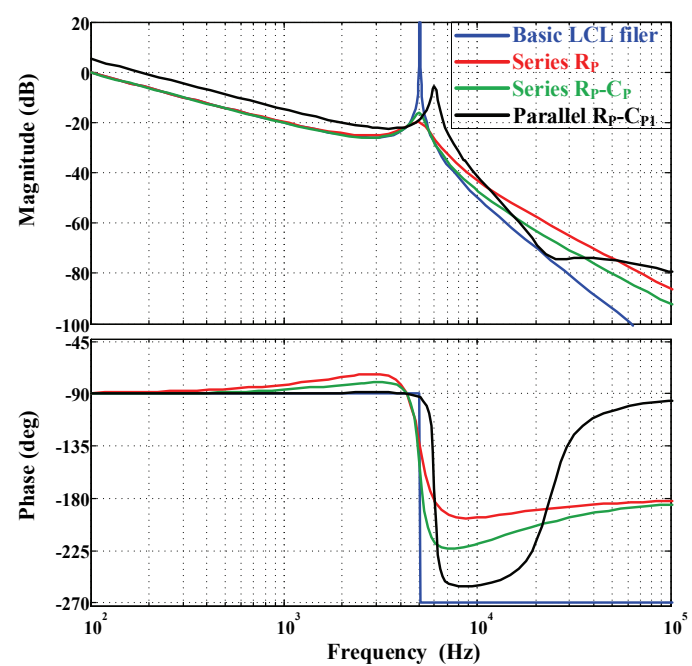

(b) LCL filter with damper $B$

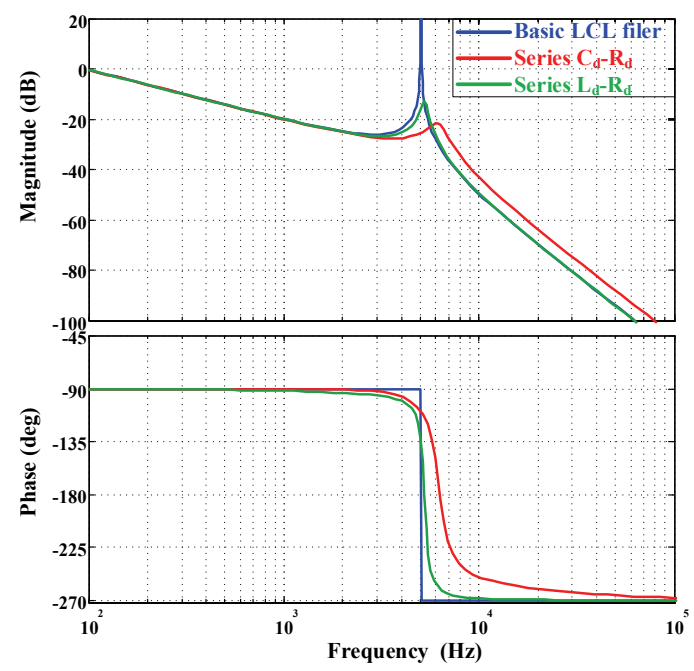

(d) LCL filter with damper $C$

Fig. 5. Frequency responses of LCL filter with each damper

primary factor, a damping circuit that causes high degradation of the attenuation ratio is not suitable. Considering only a case in which a small degradation of attenuation ratio occurs, the series $L-R$ structure in damper $D$ is reasonable for the passive damping circuit. Third, the values of the damping components should be small compared to those of $L_{i}, L_{g}$ and $C_{f}$. The series $L-R$ structure in damper $D$ has little degradation of the attenuation ratio, as mentioned above. However, the value of the damping inductor $\left(L_{d}\right)$ is not sufficiently small. This case causes additional losses in the magnetic substance, and the size of the damper increased. Finally, losses in the damping resistors should be minimal. Therefore, the impedances of the series-connected passive components should be minimal and those of the parallel-connected passive components should be large, compared to those of the filter components in the high frequency range. In addition, In terms of this point, damper $B$ and damper $C$ are not suitable because they are connected with $L_{i}$ and $L_{g}$. Thus, losses by fundamental and low-order harmonic currents are relatively higher than damper $A$ and damper $D$ that are connected with $C_{f}$. When resonant currents are ignored, losses by damping resistors in damper $A$ and damper $D$ in conditions of maximum ripple current are shown in (9) and (10) [12].

$$
\begin{gathered}
P_{\text {LOSS } . R_{f}}=\left(\frac{(1-\alpha)^{2} i_{I N V . h . p e a k}{ }^{2} \cdot L_{f 1}^{2} \omega_{s}^{2}}{\left(L_{f 1}+L_{f}\right)^{2} \omega_{s}^{2}+R_{f}^{2}}\right) \frac{R_{f}}{3} \\
P_{\text {LOSS } R_{d}}=\frac{(1-\alpha)^{2} i_{I N V . h . p e a k}{ }^{2} C_{d}^{2}}{\left[\begin{array}{l}
\left(C_{d}^{2} C_{f}^{2} L_{d}^{2}\right) \omega_{s}{ }^{4}+C_{d}{ }^{2} C_{f}{ }^{2} R_{d}{ }^{2} \omega_{s}{ }^{2} \\
-2 L_{d} C_{d} C_{f}\left(C_{d}+C_{f}\right) \omega_{s}{ }^{2}+\left(C_{d}+C_{f}\right)^{2}
\end{array}\right]} \cdot \frac{R_{d}}{3}
\end{gathered}
$$

Considering these design points, analysis of passive damping circuits for selecting reasonable dampers are 
performed using the generalized model. Damper $A$ in Fig. 4 has small passive components, but the slope of its transfer function is smaller than that of the basic LCL filter (-60 $d B / D e c$.). Therefore, securing a high attenuation ratio in the high frequency band is more difficult than for damper $D$. By contrast, the series $L-R$ structure in damper $D$ can secure a high attenuation ratio, compared to other dampers. However, $L_{d}$ in damper $D$ is designed to be larger than others. In addition, $L_{d}$ causes additional losses and decreases the power density. Thus the series $L-R$ structure in damper $D$ is not reasonable for use in the LCL filter of the grid-connected inverter. Therefore, a reasonable damper for a grid-connected inverter is the series $R-C$ structure in damper $D$, considering losses, design size, and attenuation ratio in the high frequency band. Although the series $R-C$ structure in damper $D$ has a smaller attenuation ratio than that of the series $R-L$ structures, it has relatively smaller damping resistor. The transfer function of the LCL filter with series $R-C$ structure in damper $D$ can be expressed by (11). In this equation, a damping resistor $\left(R_{d}\right)$ is designed based on the location of the added zero, as shown in (12), and (13) gives the design range of $R_{d}$. The frequency response for the design range according to $R_{d}$ is shown in Fig. 6. In (13) and Fig. 6, the minimum value of the range is the resistance which makes $-3 \mathrm{~dB}$ magnitude at the resonant frequency and its maximum value is that the added zero is located at the resonant frequency because when the added zero is located below the resonant frequency, $R_{d}$ is designed to be large. Lastly, the power loss by $R_{d}$ is shown in (14).

$$
G_{g}(s)=\frac{C_{d} R_{d} s+1}{\left[\begin{array}{l}
C_{d} C_{f} L_{g} L_{i} R_{d} s^{4}+\left(C_{d} L_{g} L_{i}+C_{f} L_{g} L_{i}\right) s^{3} \\
+\left(C_{d} L_{g} R_{d}+C_{d} L_{i} R_{d}\right) s^{2}+\left(L_{g}+L_{i}\right) s
\end{array}\right]}
$$

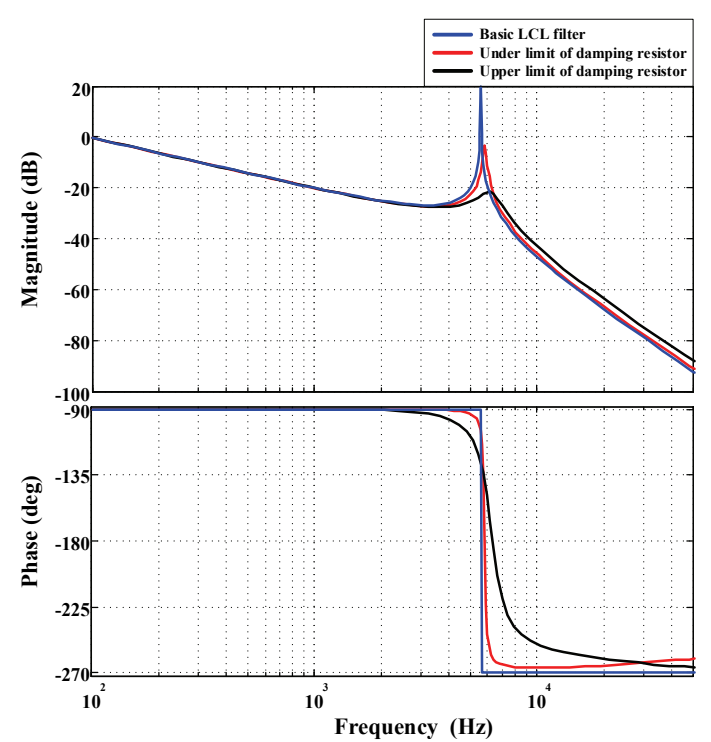

Fig. 6. Design range of LCL filter with passive damping circuits

$$
\begin{gathered}
\left.s\right|_{G_{g}(s)=0}=-\frac{1}{C_{d} R_{d}} \\
\frac{1}{16 C_{d} \omega_{\text {res }}} \leq R_{d} \leq \frac{1}{C_{d} \omega_{\text {res }}} \\
P_{\text {LOSS. } R_{d}}=\left[\frac{(1-\alpha) i_{I N V . h . p e a k} C_{d}}{C_{f}^{2} C_{d}^{2} R_{d}^{2} \omega_{s}^{2}+\left(C_{f}+C_{d}\right)^{2}}\right]^{2} \frac{R_{d}}{3}
\end{gathered}
$$

The finally selected value of $R_{d}$ is $1.0 \Omega$ that makes magnitude at resonant frequency to $-3 \mathrm{~dB}$. The designed parameters of the LCL filter and damping circuits is shown in Fig. 7(a) and its frequency response is shown in Fig. 7(b).

In the fundamental frequency band, impedances of $L_{i}, L_{g}$ and $R_{d}$ are relatively smaller than $C_{f}$ and $C_{d}$. Therefore, the voltage rating of them should be higher than phase voltage. In case of the fundamental current, it mainly flows through $L_{i}$ and $L_{g}$. Therefore, the rated current of them should be higher than the maximum phase current. Lastly, the rated power of $R_{d}$ should be higher than a calculated value by (14). However, it should be designed with sufficient rated power margin because, resonant currents are ignored when deriving (9) and (10). The design process of the LCL filter with passive damping circuits in this paper is

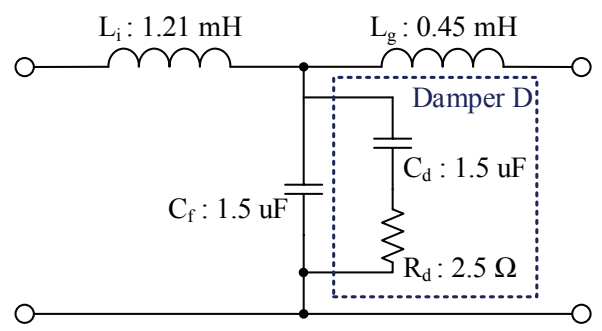

(a) Parameters of the designed LCL filter

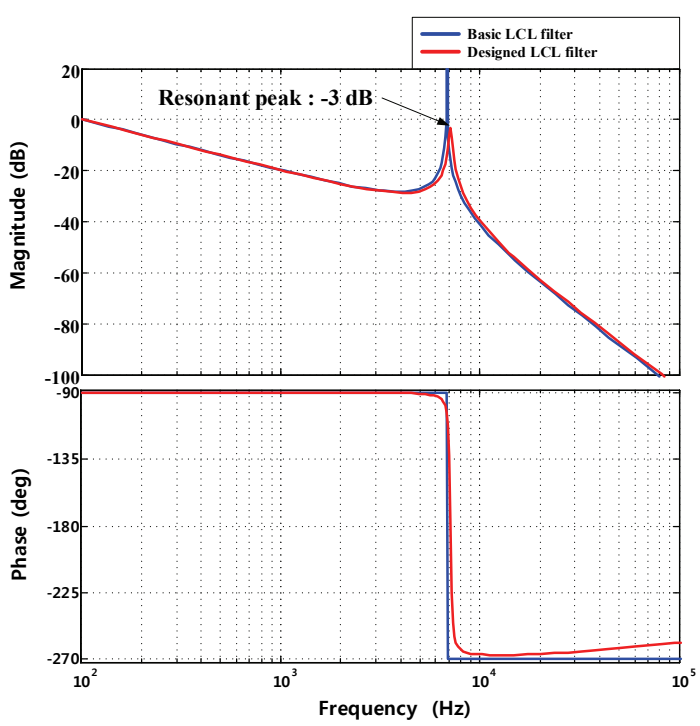

(b) Frequency response of the designed LCL filter

Fig. 7. Designed LCL filter with passive damping circuit 


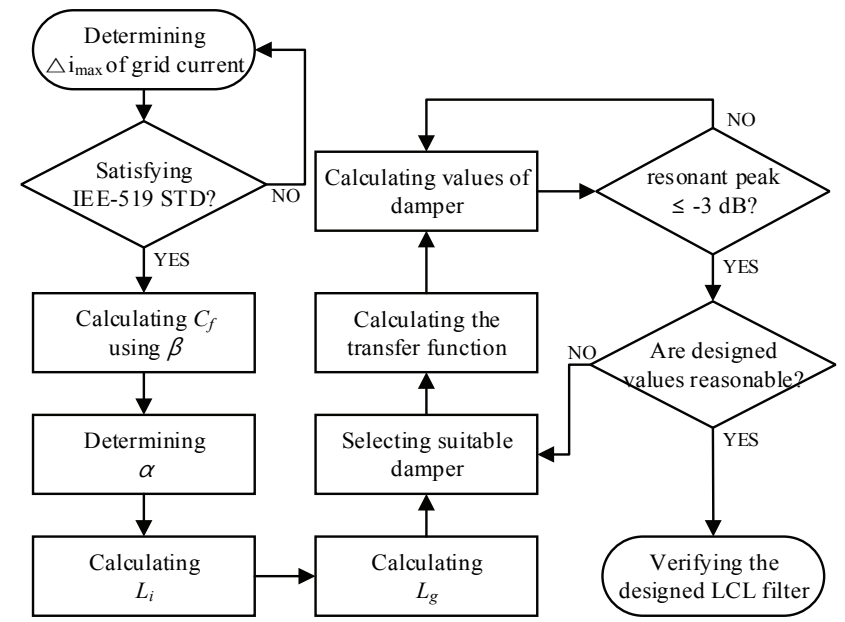

Fig. 8. The design process of LCL filter with passive damping circuits

shown in Fig. 8.

\section{Simulation and Experimental Results of Designed LCL Filter}

\subsection{Simulation results of designed LCL filter with passive damping circuit}

Simulation of the designed LCL filter with a passive damping circuit is performed to verify the validity of the designed LCL filter and passive damping circuits. The designed LCL filter is connected to a three-phase gridconnected SVPWM inverter and the simulated results are shown in Fig. 9. Fig. 9(a) indicates the inverter-side and grid-side currents and Fig. 9(b) shows the current ripple of both inverter-side and grid-side currents. In addition, Fig. 10 shows the ripple current of $R_{d}$.

Table 4 shows the evaluation of the simulation results compared to the calculated values and $\alpha$ in Table 4 is calculated using the fast Fourier transform in the simulation tool. Errors in the inverter-side current ripple as shown in Table 4 are greater than the errors in the grid-side current ripple.

This is because the resonant currents are not considered when designing the LCL filter. In the case of a grid-side current ripple, the calculated and simulation results are nearly the same, unlike in the case of the inverter-side current ripple because the resonant currents are filtered by $C_{f}$. At the switching frequency, the simulated value of $\alpha$ is also similar to the calculated value, because the harmonic current at the switching frequency is not influenced by the resonant currents. Therefore, errors in the inverter-side current ripple by the resonant current do not affect the design of the LCL filter because the grid-side current is considered mainly when designing the LCL filter. As shown in Figs. 9(a) and (b), the output currents of the
Table 4. Evaluation of simulation results of designed LCL filter

\begin{tabular}{c|c}
\hline \multicolumn{2}{c}{ Maximum current ripple of inverter side current } \\
\hline Calculated value & Simulation value \\
\hline $3.2 \mathrm{~A}_{\text {peak }}$ & $3.4 \mathrm{~A}_{\text {peak }}$ \\
\hline \multicolumn{2}{c}{ Maximum current ripple of grid side current } \\
\hline Calculated value & Simulation value \\
\hline $1.51 \mathrm{~A}_{\text {peak }}$ & $1.53 \mathrm{~A}_{\text {peak }}$ \\
\hline \multicolumn{2}{c}{$\alpha\left(I_{I N V . H} / I_{\text {Grid.H }}\right) @ 10 \mathrm{kHz}$} \\
\hline Calculated value & Simulation value \\
\hline 0.47 & 0.48 \\
\hline
\end{tabular}
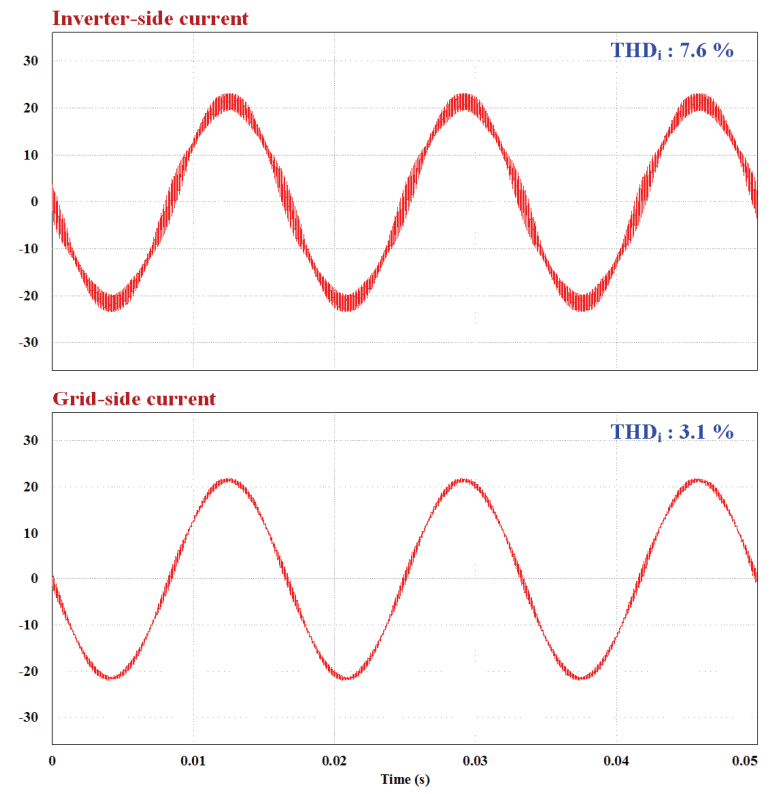

(a) Inverter-side and grid-side currents

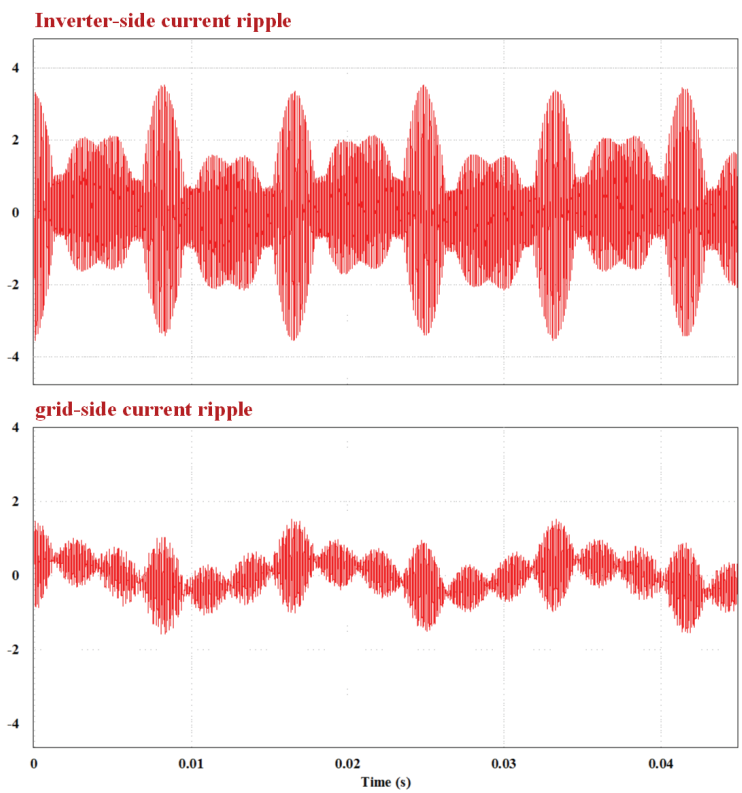

(b) Current ripple of inverter-side and grid-side currents

Fig. 9. Simulation results of the designed LCL filter 
Table 5. Prototype specification of designed LCL filter

\begin{tabular}{c|c|c}
\hline Parameter & Value & Rating \\
\hline Inverter-side inductor $\left(L_{i}\right)$ & $1.3 \mathrm{mH}$ & $18.5 \mathrm{~A}_{\mathrm{rms}}$ \\
\hline Grid-side inductor $\left(L_{g}\right)$ & $0.26 \mathrm{mH}$ & $18.5 \mathrm{~A}_{\mathrm{rms}}$ \\
\hline Filter capacitor $\left(C_{f}\right)$ & $1.5 \mathrm{uF}$ & $275 \mathrm{~V}_{\mathrm{rms}}$ \\
\hline Damping capacitor $\left(C_{d}\right)$ & $1.5 \mathrm{uF}$ & $275 \mathrm{~V}_{\mathrm{rms}}$ \\
\hline Damping resistor $\left(R_{d}\right)$ & $1.0 \Omega$ & $2 \mathrm{~W}$ \\
\hline
\end{tabular}

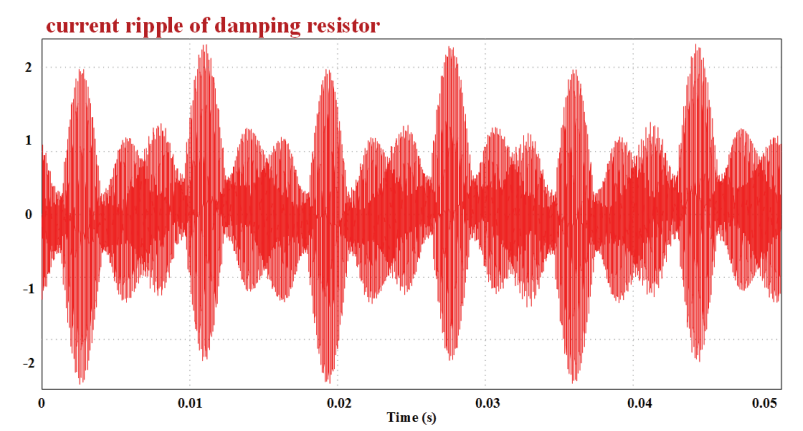

Fig. 10. Simulation results of current ripple in $R_{d}$

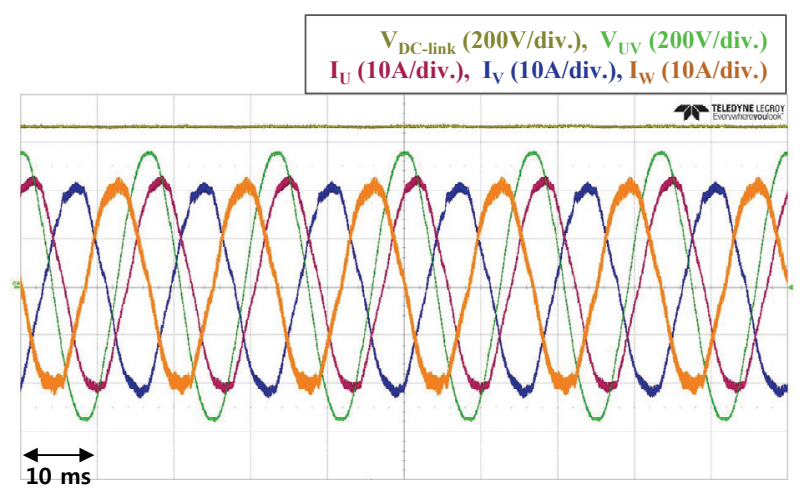

Fig. 11. Experimental results of the designed LCL filter

designed LCL filter satisfy the standards for harmonic currents. In addition, the RMS current of $R_{d}$ and total losses in $R_{d}$ are only $0.81 \mathrm{~A}_{\mathrm{rms}}$ and $1.9 \mathrm{~W}(0.6 \mathrm{~W}$ per phase $)$ at the $10 \mathrm{~kW}$ load. These results show that the designed LCL filter and passive damping circuits can be adapted to gridconnected inverters, because of the high quality of the output currents and the low losses in the damping resistor.

\subsection{Experimental results of designed LCL filter with passive damping circuit}

The designed prototype of the LCL filter based on the design process discussed in previous sections is shown in Table 5 and an experiment was performed in the gridconnected condition. In the condition of a full load (10 $\mathrm{kW}$ ), the average $\mathrm{THD}_{\mathrm{i}}$ of the output currents in Fig. 11 is $3.46 \%$, as measured by a power analyzer. The measured $\mathrm{THD}_{\mathrm{i}}$ is greater than both the simulated and calculated results because impedances of the real $\mathrm{AC}$ grid and the $\mathrm{DC}$ bias characteristics of the inductors are not reflected in the simulation. However, the experimental results still satisfy the standards of harmonic currents [11]. Therefore, the design process of the LCL filter with passive damping circuits in this paper is reasonable for grid-connected inverters.

\section{Conclusion}

In this paper, the design process of the LCL filter using simple short-circuit models without complex mathematical methods is presented. In addition, comparison and analysis of previous passive damping circuits are presented using the generalized model of the LCL filter with passive damping circuits. Based on the design process of the LCL filter and analysis results of passive damping circuits, the LCL filter with passive damping circuits for three-phase grid-connected inverters is designed. Through the simulation and experiment results of the designed LCL filter, the design process of the LCL filter with passive damping circuits are verified. Therefore, it is noted that the analysis and the proposed design process could be utilized in the grid-connected inverter systems for various applications.

\section{Acknowledgements}

This work was supported by "Human Resources Program in Energy Technology" of the Korea Institute of Energy Technology Evaluation and Planning (KETEP), granted financial resource from the Ministry of Trade, Industry \& Energy, Republic of Korea. (No.20164030200980)

\section{References}

[1] H. M. Ahn, C. Y. Oh, W. Y. Sung, J. H. Ahn, and B. K. Lee, "Analysis and design of LCL filter with passive damping circuits for three-phase grid-connected inverters," ICPE 2015-ECCE Asia, Seoul, South Korea, pp. 652-658, 1-5 June 2015.

[2] P. Channegowda and V. John, "Filter Optimization for Grid Interactive Voltage Source Inverters," IEEE Trans. Ind. Electron., vol. 57, no. 12, pp. 4106-4114, Dec. 2010.

[3] W. Wu, Y. He and T. Tang, "A New Design Method for the Passive Damped LCL and LLCL Filter-Based Single-Phase Grid-Tied Inverter," IEEE Trans. Ind. Electron., vol. 60, no. 10, pp. 4339-4350, Oct. 2013.

[4] M. Céspedes, T. Beechner, L. Xing and J. Sun, "Stabilization of Constant-Power Loads by Passive Impedance Damping," APEC 2010, Palm Springs, CA, 21-25, Feb. 2010.

[5] T. C. Wang, Z. Ye, G. Sinha, and X. Yuan, "Output Filter Design for a Grid-interconnected Three-Phase Inverter," PESC 2003, Acapulco (Mexico), Jun. 2003.

[6] Q. Liu, L. Peng, Y. Kang, S. Tang, Deliang Wu, and Y. 
Qui, "A Novel Design and Optimization Method of an LCL Filter for a Shunt Active Power Filter," IEEE Trans. Ind. Electron., vol. 61, no. 8, pp. 4000-4010, Aug. 2014.

[7] X. Guo, X. You, X. Li, R. Hao, and D. Wang, "Design Method for the LCL Filters of Three-phase Voltage Source PWM Rectifiers," J. Power Electron., vol. 12, no. 4, pp. 559-566, Jul. 2012

[8] M. Liserre, F. Blaabjerg, and S. Hansen, "Design and Control of an LCL-Filter-Based Three-Phase Active Rectifier," IEEE Trans. Ind. App., vol. 41, no. 5, pp. 1281-1291, Sept. 2015

[9] R. Peña-Alzola, M. Liserre, F. Blaabjerg, R. Sebastián, J. Dannehl, and F. Wilhelm Fuchs, "Analysis of the Passive Damping Losses in LCL-Filter-Based Grid Converters," IEEE Tran. Power Electron., vol. 28, no. 6, pp. 2642-2646, Jun. 2013,

[10] F. Golnaraghi, B. C. Kuo, "Frequency-Domain Analysis," in Automatic Control Systems, 9th ed. New York: Wiley, 2009, pp.418-426

[11] IEEE Recommended Practices and Requirements for Harmonic Control in Electrical Power Systems, IEEE standard 519-1992, May 10, 1992

[12] B. Ren, X. Sun, S. An, X. Cao, and Q. Zhang "Analysis and Design of an LCL Filter for the Threelevel Grid Connected Inverter," 2012 IEEE 7th Int. Power Electron. and Motion Control Conf., China, Harbin, pp. 2023-2027, Jun. 2012.

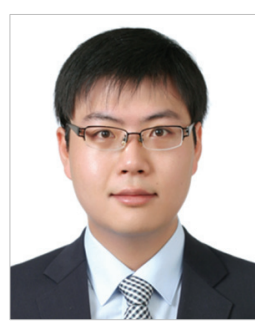

Hyo Min Ahn He received the B.S and the M.S. degrees from Sungkyunkwan University, Suwon, Korea, in 2014 and 2016, respectively. He has worked toward his Ph.D. degree in Electrical Engineering at Sungkyunkwan University, since 2016. His research interests include grid-connected inverters for ESS, multi-level inverters and high frequency filter design.

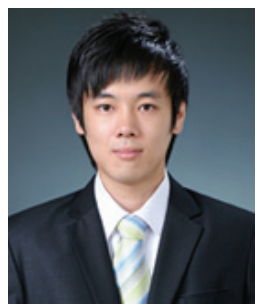

Chang-Yeol Oh He received the B.S. and the M.S. degrees from Sungkyunkwan University, Suwon, Korea, in 2011 and 2013, respectively. Since 2013, he has worked for his Ph.D in Electrical Engineering at Sungkyunkwan University. His research interests include battery charger for $\mathrm{xEVs}$, high efficiency resonant converters, ESS and DC-DC converter for renewable energy.

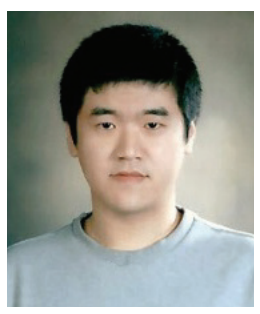

Won-Yong Sung He received the B.S. and the M.S. degrees from Sungkyunkwan University, Suwon, Korea, in 2011 and 2013, respectively. Since 2013, he has worked for his Ph.D in Electrical Engineering at Sungkyunkwan University. His research interests include EV charger and DC-DC converter for

renewable energy.

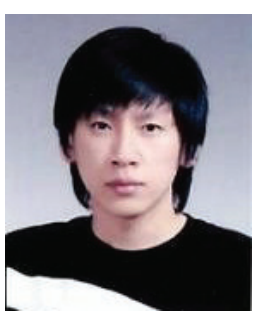

Jung-Hoon Ahn He received his M.S. degree from Sungkyunkwan University, Suwon, Korea, in 2013. Since 2013, he has been working towards his Ph.D. degree at Sungkyunkwan University. His current research interests include battery management systems (BMS), $\mathrm{DC}-\mathrm{DC}$ converters for $\mathrm{PHEV} / \mathrm{EV}$ and hybrid energy storage system (ESS).

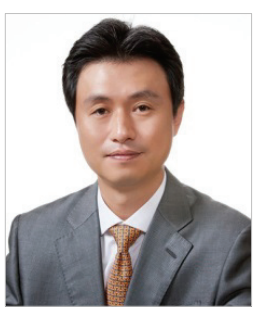

Byoung Kuk Lee He received the B.S. and the M.S. degrees from Hanyang University, Seoul, Korea, in 1994 and 1996, respectively and the Ph.D. degree from Texas A\&M University, College Station, TX, in 2001, all in electrical engineering. From 2003 to 2005, he has been a Senior Researcher at Power Electronics Group, Korea Electrotechnology Research Institute (KERI), Changwon, Korea. From 2006 Prof. Lee joins at College of Information and Communication Engineering, Sungkyunkwan University, Suwon, Korea. His research interests include on-board chargers and wireless power transfer chargers for electric vehicles, BMS algorithms, energy storage systems, hybrid renewable energy systems, dc distribution systems for home appliances, modeling and simulation, and power electronics. Prof. Lee is a recipient of Outstanding Scientists of the 21st Century from IBC and listed on 2008 Ed. of Who's Who in America and 2009 Ed. of Who's Who in the World. Prof. Lee is a Guest Associate Editor in the IEEE Transactions on Power Electronics and Associate Editor in the IEEE Transactions on Transportation Electrification. He was the Presenter for Professional Education Seminar with the topic of "OnBoard Charger Technology for EVs and PHEVs" at IEEE Applied Power Electronics Conference in 2014. Prof. Lee was the General Chair for IEEE Vehicular Power and Propulsion Conference (VPPC) in 2012 and is a member of IEC Conformity Assessment Board (CAB) from 2016. 